\title{
Personal goal setting as a mediator of the relationship between mindfulness and wellbeing
}

\author{
Simon Grégoire · Thérèse Bouffard · Carole Vezeau
}

\begin{abstract}
Although the evidence suggesting a positive relationship between mindfulness and wellbeing is rapidly accumulating, the mechanisms by which this relationship operates remain unclear. This study explored the relationship between mindfulness, wellbeing and a selfregulatory process, namely personal goal setting. It was hypothesized that people reporting higher levels of mindfulness would strive for goals having a greater degree of autonomy, which would in turn have a beneficial impact on their wellbeing. University students $(n=114)$ completed questionnaires aimed at assessing their level of mindfulness and wellbeing. They were asked to identify five personal goals they were currently pursuing and indicate the reasons (extrinsic, introjected, identified or intrinsic) they were pursuing these goals. A bootstrapping analysis supports the mediating hypothesis and suggests that students who reported being more attentive and aware tended to be engaged in personal endeavours that were more autonomously motivated, which in turn appeared to foster their wellbeing.
\end{abstract}

Keywords: mindfulness, wellbeing, self-regulatory process, personal goals

\section{Introduction}

Despite the growing evidence, from both correlational and field studies, of the beneficial impacts of mindfulness, there is a current debate over the nature of the relationship between mindfulness and wellbeing (Baer, 2010; Carmody, Baer, Lykins, \& Olendzki, 2009; Coffey \& Hartman, 2008; Coffey, Hartman, \& Fredrickson, 2010). Mindfulness has been defined in various ways in the literature. For example, Brown and Ryan (2003) define it as receptive attention to and awareness of present events and experience. According to Bishop, et al. (2004), mindfulness refers to both the self-regulation of attention to one's current experience and a particular orientation towards this experience, characterized by curiosity, openness, and acceptance. For Kabat-Zinn (2003), mindfulness involves intentionally paying sustained attention to one's ongoing sensory, cognitive, and emotional experience, without elaborating upon or judging any part of this experience.

As mentioned by several authors, the construct of mindfulness is subtle and somewhat elusive; defining it in operational terms is not an easy task (Baer, Walsh, \& Lykins, 2008). Moreover, some have pointed out that there is a tendency in the literature to use the term 'mindfulness' to refer interchangeably to a state, a series of practices designed to achieve this state, or a type of meditation. Such interchangeable use of 'mindfulness' sometimes causes confusion (Chambers, Gullone, \& Allen, 2009). For the sake of clarity, and in accordance with the definition proposed by Brown and Ryan (2003), the term 'mindfulness' is used in this paper to describe a state of consciousness which involves consciously attending to one's moment-to- 
moment experience and being aware of one's inner and outer worlds, including thoughts, emotions, sensations, actions, or surroundings.

The Mindfulness Attention Awareness Scale (MAAS) is among the most popular self-report instruments used to measure mindfulness (Brown \& Ryan, 2003). The studies conducted to date using this scale indicate that mindfulness is correlated with various wellbeing and mental health indicators (Brown, Ryan, \& Creswell, 2007). For example, compared to individuals with low levels of mindfulness, those with higher levels report feeling less stressed, anxious, depressed or impulsive (Argus \& Thompson, 2008; Brown \& Ryan, 2003; Jermann, et al., 2009; Weinstein, Brown, \& Ryan, 2009). They also report being more optimistic and more satisfied with their lives (Brown \& Ryan, 2003).

Besides these correlation studies, other studies have assessed the impact of various mindfulness-based training programs on mental health, such as the Mindfulness-Based Stress Reduction program (MBSR) (Kabat-Zinn, 1982, 2003), Mindfulness-Based Cognitive Therapy (MBCT) (Segal, Williams, \& Teasdale, 2002), Acceptance and Commitment Therapy (ACT) (Hayes, Strosahl, \& Wilson, 1999) and Dialectical Behavior Therapy (DBT) (Linehan, 1993). Although they differ in various ways, these programs share some common characteristics and all include a form of mindfulness training. This training, such as, for instance, mindfulness meditation, aims to increase an individual's capacity to cultivate attention and awareness. During meditation, an individual must consciously try to keep his attention focused on an object (e.g. one's breath, emotions or sensations) in a receptive manner, without fixating on any particular part of this experience or engaging in any secondary processing.

Various studies have demonstrated that these programs are related to positive psychological and physical outcomes. The MBSR program has received the most attention to date (Bishop, 2002). This program focuses on the cultivation of mindfulness through various activities (e.g. meditation, body scan and mindful yoga) and on the integration of this state into everyday life as a coping strategy for dealing with difficulties. It also includes group interaction, with participants sharing the challenges and achievements they have experienced upon integrating mindfulness into their lives. The program has proven to be efficacious for clinical populations with a variety of physical and mental health issues including chronic pain, cancer, heart disease, depression and anxiety (Baer, 2003; Grossman, Niemann, Schmidt, \& Walach, 2004; Irving, Dobkin, \& Park, 2009). It has also proven to be helpful for non-clinical populations (Bishop, 2002; Chiesa \& Serretti, 2009). For instance, it has helped reduce stress among nurses (Cohen-Katz, 2004; Shapiro, Astin, Bishop, \& Cordova, 2005), therapists in training (Shapiro, Brown, \& Biegel, 2007) and university students (Shapiro, Oman, Thoresen, Plante, \& Flinders, 2008). Similar to the MBSR program, MBCT was developed especially for depressed individuals. Studies on this program are promising and suggest that it significantly helps reduce the risk of relapse among these individuals (Coelho, Canter, \& Ernst, 2007). DBT was developed as a treatment for chronic suicidal and other self-injurious behaviors, which are often present in patients with severe borderline personality disorder. According to Öst (2008), even though the studies realised so far in order to assess DBT efficacy still suffer from various methodological limitations, these studies are encouraging and suggest that the therapy helps reduce symptoms among borderline patients. Recently, empirical studies have also focused on ACT. A recent review indicates that ACT is effective in various contexts (e.g. clinical and work settings) and for a wide variety of problems (e.g. depression, anxiety, phobia) (Ruiz, 2010). 


\section{The nature of the relationship between mindfulness and wellbeing}

If mindfulness has shown beneficial effects on wellbeing, little is known about the mediators and moderators through which these effects take place (Shapiro, Carlson, Astin, \& Freedman, 2006). Wellbeing is a multidimensional construct that encompasses three main components (Gallagher, Lopez, \& Preacher, 2009). Subjective wellbeing refers to the experience of high levels of pleasant emotions and moods, low levels of negative emotions and moods, and high life satisfaction (Diener, Emmons, Larsen, \& Griffin, 1985). Psychological wellbeing relies on the assumption that individuals strive to function fully and realize their unique talents. It is made up of six components: autonomy, environmental mastery, personal growth, positive relations with others, purpose in life, and self-acceptance (Ryff \& Keyes, 1995). Social wellbeing represents primarily public phenomena, focused on the social tasks (e.g., social acceptance) encountered by adults in their social lives (Keyes, 1998).

Brown et al. (2007) maintain that mindfulness may facilitate wellbeing directly:

by adding clarity and vividness to current experience and encouraging closer, moment-to-moment sensory contact with life, that is, without a dense filtering of experience through discriminatory thoughts (p. 219).

Furthermore, these authors maintain that this relationship may also operate indirectly through various self-regulatory mechanisms of action. According to them, mindfulness may foster successful self-regulation and thus have positive effects on wellbeing.

The latest proposition offered by Brown et al. (2007) recently received empirical support. For instance, some studies have indicated that the relationship between mindfulness and wellbeing may be partially mediated by emotional processes (Chambers, et al., 2009; Gratz \& Tull, 2010). In fact, a strong relationship was found between mindfulness and the use of adaptive emotion regulation strategies known to have beneficial impacts on wellbeing (Feldman, Hayes, Kumar, Greeson, \& Laurenceau, 2007; Jimenez, Niles, \& Park, 2010; Roemer, et al., 2009). Recent studies in neurobiology also suggest that mindfulness training may lead to functional and structural changes in the prefrontal cortex and the limbic systems, which are both involved in emotional regulation processes (Frewen, et al., 2010). Although the relationship between mindfulness, emotional processes and wellbeing is not yet fully understood, Hayes and Feldman (2004) argue that mindfulness training enhances emotion regulation abilities by changing an individual's relationship with their emotions. With higher levels of mindfulness, an individual can genuinely experience and express his/her emotions without over-engagement (e.g. entanglement) or under-engagement (e.g. avoidance) with them, which in turn enhances the individual's wellbeing. Emotions are simply accepted as they are, without any attempt to control, avoid or cling to them.

Studies also suggest that the relationship between mindfulness and wellbeing may be partially mediated by cognitive processes. For example, it has been shown that practicing mindfulness meditation helps reduce both thought rumination (Jain, et al., 2007) and cognitive distortions (Sears \& Kraus, 2009). It also facilitates cognitive defusion, that is, the ability to observe one's thoughts and feelings as temporary events in the mind not requiring any particular response, rather than as reflections of the self that are necessarily true or important (Sauer \& Baer, 2010). According to Hayes and Wilson (2003), this defusion process helps a person gain cognitive flexibility and adjust cognitive processing strategies to face new and unexpected conditions. It increases the range and adaptability of responses in the face of challenges and makes it possible to address these challenges consciously rather than merely automatically (see also Moore \& Malinowski, 2009). 
Mindfulness may also facilitate wellbeing indirectly through the enhancement of goalsetting processes, although this idea has not yet been investigated. Personal goal setting (e.g., launching a company) is a self-regulatory process that affects an individual's behaviours i.e., choosing to pursue personal goals influences an individual's actions. The type of goal an individual strives for also influences his wellbeing in several ways (Little, Salmela-Aro, \& Phillips, 2007). For instance, people who are engaged in interpersonal goals (e.g. doing voluntary work at the community centre) tend to report higher subjective wellbeing than people who are engaged in intrapersonal or more self-oriented goals (e.g. jogging every night) (Salmela-Aro \& Little, 2007). People who are committed to personal endeavours that are manageable, meaningful and supported, generally report higher wellbeing than people who are engaged in goals that do not have these characteristics (Little \& Chambers, 2000).

The reasons people pursue goals also influence their wellbeing. Ryan and Connell (1989) proposed a continuum of reasons for acting, ranging from external to introjected (controlled) to identified to intrinsic (autonomous) reasons. According to Self-Determination Theory (Ryan \& Deci, 2000), autonomous goals (e.g., striving for personal growth or enjoyment) are inherently rewarding because they satisfy innate psychological needs such as relatedness, competence and autonomy. When people are autonomously motivated, they experience volition, or a selfendorsement of their actions (Deci \& Ryan, 2008). In contrast, controlled goals (e.g., those that are pursued to please someone else or to gain fame) do not directly satisfy these psychological needs to the same extent; people tend to experience pressure to think, feel, or behave in particular ways (Deci \& Ryan, 2008). Several longitudinal studies have shown that the pursuit of autonomous goals is positively related to various wellbeing indicators whereas the pursuit of controlled goals is negatively related to these indicators (see Sheldon \& Kasser, 2001). Simply put, wellbeing levels improve when individuals are autonomous and feel volitional in pursuing their goals.

Are people who report higher levels of mindfulness more inclined to embark on personal endeavours for autonomous and self-determined reasons than people who report low mindfulness? According to Deci and Ryan (2008), the development of integrated, autonomous human functioning depends on awareness, suggesting that awareness may facilitate the selection of behaviours, actions and goals that are more consistent with one's needs, values and interests (Ryan \& Deci, 2000). Brown and Ryan (2003) state “...mindfulness may facilitate wellbeing through self-regulated activity and fulfillment of the basic psychological needs for autonomy..., competence, and relatedness" (p. 824). Thus, attention and awareness may help individuals disengage from habits, reactivity and behavioural patterns, but also actions driven by external factors. Moreover, attention and awareness may help individuals avoid controlled goals and be more inclined to strive for self-endorsed or freely chosen ones. In other words, mindfulness may favour the selection of self-determined, autonomous goals, which in turn may enhance wellbeing. Although conceptually appealing, this idea has not yet been explored in depth.

\section{The present study}

The purpose of this study was to explore the relationship between mindfulness, personal goal setting and wellbeing. It was hypothesized that individuals who reported high levels of mindfulness would be pursuing more autonomous goals (those that rely on intrinsic or identified motives), and that those individuals would also report high levels of wellbeing. 
Therefore, it was predicted that:

H1) High levels of mindfulness are significantly related to higher levels of wellbeing.

H2) High levels of mindfulness are significantly related to autonomous goals.

H3) The relationship between high levels of mindfulness and high levels of wellbeing are mediated by autonomous personal goal setting.

\subsection{Method}

\subsubsection{Participants and procedure}

One hundred and fourteen (114) university students volunteered to participate in the study. All participants were French-speaking and the majority were women $(90 \%)$ and at the undergraduate level $(90 \%)$. Their ages ranged from 19 to 59 years (mean age $=26.82 ; S D=7.44$ ). Participants filled out questionnaires about mindfulness, wellbeing and personal goals at their own pace during a collective session held during regular course time.

\subsubsection{Measures}

Mindfulness was assessed using the MAAS (Brown \& Ryan, 2003) validated in French by Jermann, et al. (2009). MAAS was selected because the scale is short and has good psychometric validity (MacKillop \& Anderson, 2007). This 15-item scale addresses cognitive, emotional, physical, interpersonal, and general domains in an indirect way (e.g. "I find myself doing things without paying attention"). Respondents must indicate how frequently they experience the situation described in each item using a 6-point Likert scale ranging from 1 (almost always) to 6 (almost never). High scores reflect more present moment awareness. Brown and Ryan (2003) assumed that indirect items would be more "diagnostic" than direct claims of mindfulness since mindless states are more common than mindful states (Brown \& Ryan, 2003, p. 825). Therefore, people completing the MAAS are asked to rate how often they have experiences of mindlessness (e.g. acting on automatic pilot). The psychometric properties of the French version are similar to those reported for the original version by Brown \& Ryan (2003). This version is based on a single factor model and has good internal consistency $(\alpha=.84)$. The indices of internal consistency for all instruments used in this study are reported in Table 1.

Two wellbeing components were measured in this study. Subjective wellbeing (SWB) was measured with two widely employed assessment instruments, namely; the Positive and Negative Affect Schedule (PANAS) (Watson, Clark, \& Tellegen, 1988) validated in French by Gaudreau, Sanchez, and Blondin (2006) and the Satisfaction With Life Scale (SWLS) (Diener, Emmons, Larsen, \& Griffin, 1985) validated in French by Blais, Vallerand, Pelletier, and Brière (1989). The PANAS is a 20-item scale that measures positive and negative affects. It contains ten positive mood adjectives such as "proud" and ten negative mood adjectives such as "scared." Participants were asked to report the extent to which they had experienced these moods during the previous month using a 5-point Likert scale ranging from 1 (very slightly or not at all) to 5 (very much). The SWLS is a 5-item scale that measures life satisfaction. It includes items such as "The conditions of my life have been excellent" and is based on a Likert scale ranging from 1 (totally disagree) to 7 (totally agree). In this study, SWB was cast as a hierarchical construct spanning three primary components and conceptualized as a higher order latent factor (Gallagher, et al., 2009). Accordingly, a SWB score was computed by summing positive affect and life satisfaction and subtracting negative affect (Sheldon \& Hoon, 2007).

Psychological wellbeing (PWB) was measured with the French version of the Scales of Psychological Well-Being (Lapierre \& Desroches, 1997; Ryff \& Keyes, 1995). Two sub-scales were 
used in this study: the self acceptance scale ("In general, I feel confident and positive about myself") and the purpose in life scale ("I am an active person in carrying out the plans I set for myself"). Both sub-scales are based on a 6-point agreement Likert scale and include 14 items each. A PWB score was created by summing purpose in life and self-acceptance scores.

Personal goals were measured using a methodology inspired by both Little (1983) and Sheldon and Kasser $(1995,1998)$. Participants were first asked to write down five important personal goals in which they were currently engaged and then to rate each of them with regard to the following dimensions, using a scale ranging from 0 to 10 :

External motivation. "Sometimes, we pursue a goal because someone else wants us to or because we feel our situation obliges us to. A score of 10 indicates that you are engaged in this goal because someone else or your situation drives you to do so. A score of 0 indicates that you are not at all engaged in this goal for this reason."

Introjected motivation. "Sometimes, we pursue a goal because we think we would feel guilty, anxious or ashamed if we didn't. A score of 10 indicates that you are engaged in this goal to avoid feeling guilty, anxious or ashamed. A score of 0 indicates that you are not at all engaged in this goal for this reason."

Identified motivation. "Sometimes, we pursue a goal because we really believe it is an important goal. A score of 10 indicates that you are engaged in this goal because you're convinced it is important. A score of 0 indicates you are not at all engaged in this goal for this reason."

Intrinsic motivation. "Sometimes, we pursue a goal because of the fun and enjoyment it will bring. A score of 10 indicates that you are engaged in this goal because of the fun and enjoyment it brings you. A score of 0 indicates that you are not at all engaged in this goal for this reason."

According to Sheldon and Kasser (1998): "these four reasons represent a continuum of perceived locus of causality for action ranging from controlled and non-self-determined to autonomous and self-determined" (p.1322). As recommended by these authors, a selfdetermination score was first created for each goal by doubling the external and intrinsic scores (the two extremes of the continuum) and then subtracting the external and introjected scores from the identified and intrinsic scores (Sheldon \& Kasser, 1995, 1998). Thus, the following formula was used to calculate a self-determination score for each of the five goals: [(intrinsic motivation*2) + (identified motivation) $]-[($ external motivation*2) + (introjected motivation) . This procedure led to the creation of 5 self-determination scores for each participant. As the internal consistency of these scores was acceptable (see Table 1.), an aggregate selfdetermination score was then computed for each participant by summing up the selfdetermination scores for their five goals. A high self-determination score indicates that a person is engaged in personal goals for autonomous and self-determined motives; a low score indicates that she or he is engaged in personal goals for controlled and non-self-determined motives.

\section{Results}

Table 1 presents the descriptive statistics and indices of internal consistency for the scales included in this study. Some variables were either positively skewed (for example the negative affects scale) or negatively skewed (the satisfaction with life scale), which is not surprising considering the non-clinical population under study. 
Table 1. Descriptive statistics and internal consistency for all variables

\begin{tabular}{llllrl}
\hline Variables & Min & Max & $M$ & \multicolumn{1}{c}{ SD } & $\alpha$ \\
\hline Mindfulness & 2.20 & 5.20 & 3.98 & .55 & .72 \\
Satisfaction with life & 1.60 & 6.80 & 5.17 & 1.13 & .85 \\
Positive affects & 1.30 & 4.90 & 3.69 & .67 & .88 \\
Negative affects & 1.00 & 4.10 & 2.19 & .66 & .84 \\
Purpose in life & 2.93 & 6.00 & 4.90 & .66 & .81 \\
Self-acceptance & 4.57 & 5.93 & 4.51 & .97 & .93 \\
Self-determination & -23 & 150 & 69.72 & 42.74 & .70 \\
\hline
\end{tabular}

In order to test the first hypothesis, correlation coefficients were computed between mindfulness and all wellbeing indicators. Mindfulness was positively correlated to both positive affects $(r=.14, p>.001)$ and satisfaction with life $(r=.28, p<.001)$ scores while negatively correlated to the negative affects score $(r=-.40, p<.001)$. Mindfulness was also positively correlated to purpose in life $(r=.41, p<.001)$ and self-acceptance scores $(r=.44, p<.001)$. The overall correlation coefficients between mindfulness and SWB and PWB are presented in Table 2. Taken together, these results support hypothesis 1 .

As shown in Table 2, mindfulness was also positively linked to the self-determination score $(r=.44, p<.001)$, supporting hypothesis 2 .

Table 2. Pearson Product Moment correlation coefficients between mindfulness, wellbeing and self-determination

\begin{tabular}{lllll}
\hline \multicolumn{1}{c}{ Variables } & 1. & 2. & 3. & 4. \\
\hline 1. Mindfulness & & & & \\
2. SWB & $.38^{* *}$ & & & \\
3. PWB & $.44^{* *}$ & $.77^{* * *}$ & & \\
4.Self-determination & $.44^{* * *}$ & $.36^{* * *}$ & $.44^{* * *}$ & \\
\hline Note: ${ }^{*} p .05,{ }^{* *} p<.01,{ }^{* * *} p<.001$ & & &
\end{tabular}

In order to test the third hypothesis, the Baron and Kenny's (1986) causal step strategy was used based on paths described in figure 1 .

The effect of mindfulness on SWB (path $\mathrm{c}: \beta=.575, p=.000$ ) and PWB (path $\mathrm{c}: \beta=1.050, p=$ .000 ) was significant. We found significant effect of mindfulness on self-determination (path a: $\beta=2.171, p=.000$ ) and to a lesser extent for self-determination on SWB (path $b: \beta=.083 . p=.023$ ) and PWB (path $b: \beta=.163, p=.003$ ). The effect of mindfulness on SWB (path $c^{\prime}: \beta=.393, p=.032$ ) and PWB (path $c^{\prime}: \beta=.695, p=.010$ ) was reduced but remains significant when the effect of selfdetermination was controlled.

The significance of the indirect effect was tested with the bootstrapping methodology developed by Preacher and Hayes (2008). In essence,

this nonparametric procedure is a computationally intensive method that involves repeatedly sampling from the data set and estimating the indirect effect in each resampled data set (Preacher \& Hayes, 2008, p. 880). 
Figure 1. Causal steps mediation test

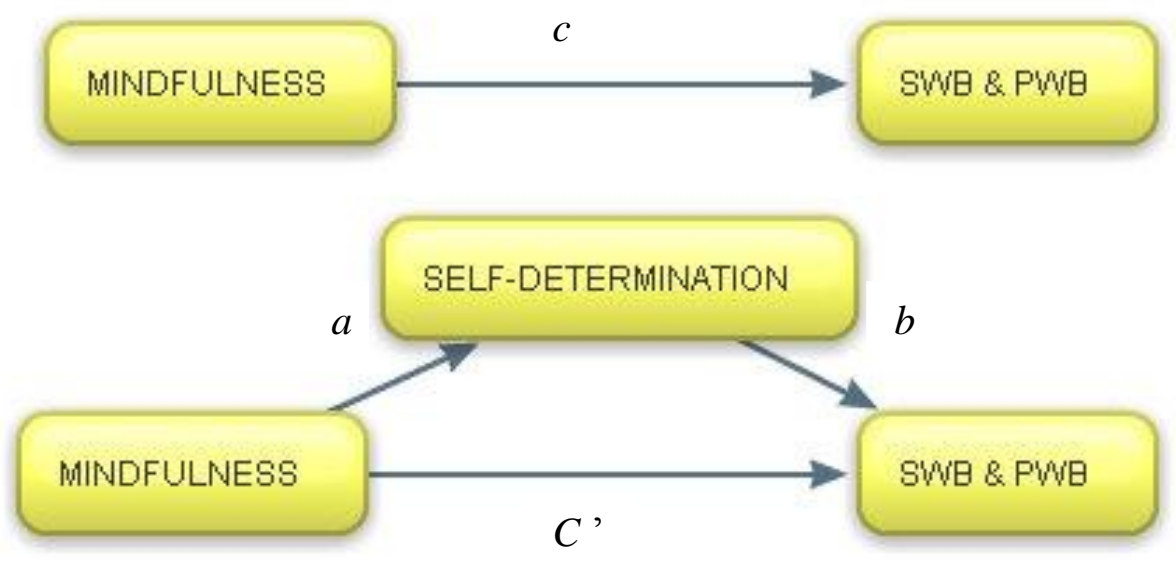

The bootstrapping sampling distributions of the indirect effects are empirically generated by taking a sample (with replacement) of size $n$ from the entire data set and calculating the indirect effects in the resamples. Point estimates and 95\% confidence intervals are used to estimate for the indirect effects. Point estimates are considered significant in the case zero is not contained in the $95 \%$ CI. Table 3 presents the results of the bootstrapping analysis conducted to test the mediation effect of mindfulness on wellbeing variables through self-determination.

Table 3. Mediation of the effect of mindfulness on subjective and psychological wellbeing through self-determination

\begin{tabular}{|c|c|c|c|c|c|c|}
\hline & \multicolumn{3}{|l|}{ SWB } & \multicolumn{3}{|l|}{ PWB } \\
\hline & \multirow{2}{*}{$\begin{array}{l}\text { Point } \\
\text { estimate }\end{array}$} & \multicolumn{2}{|c|}{ BCa $95 \%$ CI } & \multirow{2}{*}{$\begin{array}{l}\text { Point } \\
\text { estimate }\end{array}$} & \multicolumn{2}{|c|}{ BCa 95\% CI } \\
\hline & & Lower & Upper & & Lower & Upper \\
\hline Self-determination & .181 & .043 & .3981 & .354 & .151 & .704 \\
\hline
\end{tabular}

Note: The MAAS was used as the predictor variable, the self-determination score was used as the mediator variable, SWB and PWB scores were used as criteria variables. $\mathrm{CI}=$ confidence interval; $\mathrm{BCa}=$ bias corrected and accelerated; 5,000 bootstrap samples.

Table 3 shows that the 0 is not included in the bias-corrected and accelerated confidence interval used in this analysis for any of the wellbeing scores. This result suggests that an indirect effect is significantly different from zero at $p<.05$ (two tailed) for SWB and PWB and that self-determination partially mediates the relationship between mindfulness and wellbeing. This suggests that individuals who report being more mindful tend to be engaged in personal endeavours that are more autonomously motivated, which in turn fosters their wellbeing.

\section{Discussion}

This study aimed to test the following three hypotheses: a) higher levels of mindfulness are significantly related to higher levels of wellbeing (H1); b) higher levels of mindfulness are significantly related to autonomous goals (H2); and c) the relationship between higher levels of 
mindfulness and higher levels of wellbeing are mediated by autonomous personal goal setting (H3).

Our findings confirmed that mindfulness was significantly correlated with both subjective and psychological wellbeing. This finding is coherent with the results obtained in other correlational studies involving both clinical and non-clinical samples (Brown \& Ryan, 2003; Coffey \& Hartman, 2008).

As hypothesized, mindfulness was also related to the motives underpinning personal goals. A distinction was made in this study between autonomous (identified and intrinsic) and controlled (introjected and extrinsic) goals. Participants with higher mindfulness scores reported more autonomous personal goals than those with lower mindfulness scores. This result supports previous research (Brown \& Ryan, 2003; Deci \& Ryan, 2008; Ryan \& Deci, 2000) and suggests that mindfulness brings clarity to actions. It may help people choose personal goals that better serve their need for autonomy and self-determination. As Brown, et al. (2007) argue:

the receptively observant processing of internal and external information that characterizes mindfulness facilitates the healthy regulation of action through the provision of choice that is informed by abiding needs, values, and feelings and their fit with situational options and demands. That is, the fuller awareness afforded by mindfulness facilitates more flexible, adaptive responses to events, and helps to minimize automatic, habitual, or impulsive reactions (p.223).

Finally, our findings indicate that the motives underpinning personal goals act as a mediator in the relationship between mindfulness and wellbeing. Individuals who report being more attentive and aware tend to be engaged in personal endeavours that are more autonomously motivated, which in turn fosters their wellbeing. This suggests that in addition to emotion and cognition processes, goal-setting processes may also help explain the mechanisms by which mindfulness impacts on wellbeing. However, finding a statistically significant indirect effect that is supportive of mediation does not prove any causal pattern. Further experimental studies are needed to explore causal patterns between mindfulness, personal goals and wellbeing.

\section{Implications for practice}

To our knowledge, this study is the first to have explored the relationship between mindfulness, wellbeing and goal setting. Taken together, the results provide evidence that may support the integration of mindfulness interventions as a component of psychotherapy (Didonna, 2008; Germer, Siegel, \& Fulton, 2005) and counselling sessions (Stauffer, 2007). The results suggest that it may be especially beneficial to bring mindfulness into settings in which defining and clarifying personal life goals is important. By helping their clients cultivate their mindfulness, counsellors and therapists may assist them to select goals that are driven by autonomous motives rather than controlled ones. Among the mindfulness-based training programs described above, ACT and DBT are the only ones where concrete steps are taken in order to simultaneously help clients cultivate their mindfulness and set self-concordant goals. The results of this study suggest that it might be extremely valuable to do so, especially with depressed or anxious individuals. As some authors suggest (Segal, et al., 2002), when people feel anxious or depressed, they tend to act impulsively, automatically, or attempt to avoid difficult private experiences (Mitmansgruber, Beck, Höfer, \& Schüßler, 2009). Cultivating mindfulness may allow the awareness to set personal goals that are more self-concordant. 


\title{
7. Limitations and implications for research
}

The present study has limitations. First, the sample was small and rather homogeneous $(90 \%$ of students were females). Moreover, a large proportion of the goals identified by students were either academic (e.g., complete my bachelor's degree) or recreational (e.g., learn to play the guitar). A replication of this study with a larger and more heterogeneous sample in which people endorse different kinds of personal endeavours would make it to possible to test whether our findings can be generalized. Moreover, this study was based on a correlation design. Further research using experimental designs would certainly be beneficial in order to better understand the causal pattern between personal goal setting, mindfulness and wellbeing. Finally, the conceptualization of wellbeing was narrow in this study. The indicators used were aimed at assessing two components, namely subjective and psychological wellbeing. As Gallagher, et al. (2009) showed, wellbeing also relies on a social component. Unfortunately, the latter was not measured in this study due to time constraints. In the future, it would be interesting to see if similar results could be obtained with social wellbeing indicators such as the one developed by Keyes (1998).

Findings of this study suggest some promising areas of investigation for future research. For example, besides the MAAS, various scales have been developed in order to measure mindfulness: the Freiburg Mindfulness Inventory (FMI; Walach, Buchheld, Buttennmüller, Kleinknecht, \& Schmidt, 2006), the Cognitive and Affective Mindfulness Scale (CAMS; Feldman, et al., 2007), the Kentucky Inventory of Mindfulness Skills (KIMS; Baer, Smith, \& Allen, 2004) and the Southampton Mindfulness Questionnaire (SMQ; Chadwick, et al., 2008). According to work done by Baer, Smith, Hopkins, Krietemeyer, \& Toney (2006), these questionnaires encompass five distinct factors: act with awareness, non judging, non reactivity, describe and observe. The MAAS has been designed mainly to measure the act with awareness factor (Brown \& Ryan, 2003). Therefore, future studies might investigate whether or not the patterns of relationships presented here hold with other questionnaires aimed at assessing other factors of mindfulness identified by Baer et al. (2006).

Future research could also be conducted on goals types. The types of goals students were engaged in (academic, professional, health, interpersonal, etc.) were analyzed for exploratory purposes but were not part of this study. To use Sheldon and Kasser's (2001) words, we were interested in why people were pursuing their goals, rather than what types of goals they were pursuing. For example, is a person higher on mindfulness, more engaged in interpersonal (e.g., take care of one's family members) or community projects (e.g., volunteer at Greenpeace)? This might be an interesting area of investigation since various authors have suggested that mindfulness training might be associated with more compassion (Gilbert, 2009) and ecologically responsible behaviour (Brown \& Kasser, 2005).

In summary, this study involving a non-clinical population provides empirical support for the relationship between mindfulness and wellbeing and suggests that this relationship is partially mediated by personal goal setting.

\author{
Authors \\ Simon Grégoire \\ Université du Québec à Montréal \\ gregoire.simon@uqam.ca \\ Thérèse Bouffard \\ Université du Québec à Montréal, Montréal, Qc. Canada
}


Carole Vezeau

Université du Québec à Montréal, Montréal, Qc. Canada

\section{Publishing Timeline}

Received 7 December 2012

Accepted 31 March 2012

Published 29 August 2012

\section{References}

Argus, G., \& Thompson, M. (2008). Perceived social problem solving, perfectionism, and mindful awareness in clinical depression: An exploratory study. Cognitive Therapy and Research, 32(6), 745-757. http://dx.doi.org/10.1007/s10608-006-9102-1

Baer, R. A., Smith, G. T., \& Allen, K. B. (2004). Assessment of mindfulness by self-report: The Kentucky inventory of mindfulness skills. Assessment, 11(3), 191-206. http://dx.doi.org/10.1177/1073191104268029

Baer, R. A. (2003). Mindfulness training as a clinical intervention: A conceptual and empirical review. Clinical Psychology: Science and Practice, 10(2), 125-143. http://dx.doi.org/10.1093/clipsy.bpg015

Baer, R. A. (2010). Assessing mindfulness and acceptance processes in clients: Illuminating the theory and practice of change. Oakland, CA, US: Context Press/New Harbinger Publications.

Baer, R. A., Smith, G. T., Hopkins, J., Krietemeyer, J., \& Toney, L. (2006). Using self-report assessment methods to explore facets of mindfulness. Assessment, 13, 27-45. http://dx.doi.org/10.1177/1073191105283504

Baer, R. A., Walsh, E., \& Lykins, E. L. B. (2008). Assessment of mindfulness. In F. Didonna (Ed.), Clinical handbook of mindfulness. New-York: Springer.

Baron, R. M., \& Kenny, D. A. (1986). The moderator-mediator variable distinction in social psychological research: Conceptual, strategic, and statistical considerations. Journal of Personality and Social Psychology, 51(6), 1173-1182. http://dx.doi.org/10.1037/0022-3514.51.6.1173

Bishop, S. R. (2002). What do we really know about mindfulness-based stress reduction? Psychosomatic Medicine, 64(1), 71-83.

Bishop, S. R., Lau, M. A., Shapiro, S. L., Carlson, L., Anderson, N. D., Carmody, J., Segal, Z. V., et al. (2004). Mindfulness: A proposed operational definition. Clinical Psychology: Science and Practice, 11(3), 230-241. http://dx.doi.org/10.1093/clipsy.bph077

Blais, M. R., Vallerand, R. J., Pelletier, L. G., \& Brière, N. M. (1989). L'échelle de satisfaction de vie: Validation canadienne-française $\mathrm{du}$ "satisfaction with life scale". Revue canadienne des sciences $d u$ comportement, 21(2), 210-223.

Brown, K., \& Kasser, T. (2005). Are psychological and ecological well-being compatible? The role of values, mindfulness, and lifestyle. Social Indicators Research, 74, 349-368. http://dx.doi.org/10.1007/s11205-004-8207-8

Brown, K ., \& Ryan, R. M. (2003). The benefits of being present: Mindfulness and its role in psychological well-being. Journal of Personality and Social Psychology, 84(4), 822-848. http://dx.doi.org/10.1037/00223514.84.4.822

Brown, K ., Ryan, R. M., \& Creswell, J. D. (2007). Mindfulness: Theoretical foundations and evidence for its salutary effects. Psychological Inquiry, 18(4), 211-237. http://dx.doi.org/10.1080/10478400701598298

Carmody, J., Baer, R. A., Lykins, E. L. B., \& Olendzki, N. (2009). An empirical study of the mechanisms of mindfulness in a mindfulness-based stress reduction program. Journal of clinical psychology, 65(6), 613-626. http://dx.doi.org/10.1002/jclp.20579

Chadwick, P., Hember, M., Symes, J., Peters, E., Kuipers, E., \& Dagnan, D. (2008). Responding mindfully to unpleasant thoughts and images: Reliability and validity of the Southampton mindfulness questionnaire (SMQ). The British journal of clinical psychology the British Psychological Society, 47(Pt 4), 451-455. 
Chambers, R., Gullone, E., \& Allen, N. B. (2009). Mindful emotion regulation: An integrative review. Clinical Psychology Review, 29(6), 560-572. http://dx.doi.org/10.1016/j.cpr.2009.06.005

Chiesa, A., \& Serretti, A. (2009). Mindfulness-based stress reduction for stress management in healthy people: A review and meta-analysis. The journal of Alternative and Complementary Medicine, 15(5), 593600. http://dx.doi.org/10.1089/acm.2008.0495

Coelho, H. F., Canter, P. H., \& Ernst, E. (2007). Mindfulness-based cognitive therapy: Evaluating current evidence and informing future research. Journal of Consulting and Clinical Psychology, 75(6), 1000-1005. http://dx.doi.org/10.1037/0022-006X.75.6.1000

Coffey, K. A., \& Hartman, M. (2008). Mechanisms of action in the inverse relationship between mindfulness and psychological distress. Complementary Health Practice Review, 13(2), 79-91. http://dx.doi.org/10.1177/1533210108316307

Coffey, K. A., Hartman, M., \& Fredrickson, B. (2010). Deconstructing mindfulness and constructing mental health: Understanding mindfulness and its mechanisms of action. Mindfulness, 1(4), 235-253. http://dx.doi.org/10.1007/s12671-010-0033-2

Cohen-Katz, J. (2004). Mindfulness-based stress reduction and family systems medicine: A natural fit. Families, Systems, \& Health, 22(2), 204-206. http://dx.doi.org/10.1037/1091-7527.22.2.204

Deci, E. L., \& Ryan, R. M. (2008). Self-determination theory: A macrotheory of human motivation, development, and health. Canadian Psychology, 49(3), 182-185. http://dx.doi.org/10.1037/a0012801

Didonna, F. (2008). Clinical handbook of mindfulness. New-York: Springer.

Diener, E., Emmons, R. A., Larsen, R. J., \& Griffin, S. (1985). The satisfaction with life scale. Journal of Personality Assessment, 49, 71-76. http://dx.doi.org/10.1207/s15327752jpa4901 13

Feldman, G., Hayes, A., Kumar, S., Greeson, J., \& Laurenceau, J.-P. (2007). Mindfulness and emotion regulation: The development and initial validation of the Cognitive and Affective Mindfulness ScaleRevised (CAMS-R). Journal of Psychopathological Behavior Assessment, 29, 177-190.

http://dx.doi.org/10.1007/s10862-006-9035-8

Frewen, P. A., Dozois, D. J. A., Neufeld, R. W. J., Lane, R. D., Densmore, M., Stevens, T. K., \& Lanius, R. A. (2010). Individual differences in trait mindfulness predict dorsomedial prefrontal and amygdala response during emotional imagery: An fMRI study. Personality and Individual Differences, 49(5), 479484. http://dx.doi.org/10.1016/j.paid.2010.05.008

Gallagher, M. W., Lopez, S. J., \& Preacher, K. J. (2009). The hierarchical structure of well-being. Journal of Personality, 77(4), 1025-1050. http://dx.doi.org/10.1111/j.1467-6494.2009.00573.x

Gaudreau, P., Sanchez, X., \& Blondin, J.-P. (2006). Positive and negative affective states in a performancerelated setting: Testing the factorial structure of the PANAS across two samples of French-Canadian participants. European Journal of Psychological Assessment, 22(4), 240-249.

http://dx.doi.org/10.1027/1015-5759.22.4.240

Germer, C. K., Siegel, R. D., \& Fulton, P. R. (2005). Mindfulness and psychotherapy. New-York: The Guilford Press.

Gilbert, P. (2009). The compassionate mind. A new approach to life's challenges. Oakland: New Harbinger Publications.

Gratz, K. L., \& Tull, M. T. (2010). Emotion regulation as a mechanism of change in acceptance- and mindfulness-based treatments. In R. A. Baer (Ed.), Assessing mindfulness and acceptance processes in clients: Illuminating the theory and practice of change. (pp. 107-133). Oakland, CA, US: Context Press/New Harbinger Publications.

Grossman, P., Niemann, L., Schmidt, S., \& Walach, H. (2004). Mindfulness-based stress reduction and health benefits: A meta-analysis. Journal of Psychosomatic Research, 57(1), 35-43. http://dx.doi.org/10.1016/S0022-3999(03)00573-7

Hayes, A. M., \& Feldman, G. (2004). Clarifying the construct of mindfulness in the context of emotion regulation and the process of change in therapy. Clinical Psychology: Science and Practice, 11(3), 255262. http://dx.doi.org/10.1093/clipsy.bph080

Hayes, S. C., \& Wilson, K. G. (2003). Mindfulness: Method and process. Clinical Psychology: Science and Practice, 10(2), 161-165. http://dx.doi.org/10.1093/clipsy.bpg018 
Hayes, S. C., Strosahl, K. D., \& Wilson, K. G. (1999). Acceptance and Commitment Therapy. An experimential approach to behavior change. New-York: The Guilford Press.

Irving, J. A., Dobkin, P. L., \& Park, J. (2009). Cultivating mindfulness in health care professionals: A review of empirical studies of mindfulness-based stress reduction (MBSR). Complementary Therapies in Clinical Practice, 15, 61-66. http://dx.doi.org/10.1016/j.ctcp.2009.01.002

Jain, S., Shapiro, S. L., Swanick, S., Roesch, S. C., Mills, P. J., Bell, I., \& Schartz, G. E. R. (2007). A randomized controlled trial of mindfulness meditation versus relaxation training: Effects on distress, positive states of mind, rumination, and distraction. Annals of Behavioral Medicine, 33, 11-21. http://dx.doi.org/10.1207/s15324796abm3301 2

Jermann, F., Billieux, J., LarØi, F., d'Agembeau, A., Bondolfi, G., Zermatten, A., \& Van der Linden, M. (2009). Mindful Attention Awareness Scale (MAAS): Psychometric properties of the French translation and exploration of its relations with emotion regulation strategies. Psychological Assessment, 21(4), 506-514. http://dx.doi.org/10.1037/a0017032

Jimenez, S. S., Niles, B. L., \& Park, C. L. (2010). A mindfulness model of affect regulation and depressive symptoms: Positive emotions, mood regulation expectancies, and self-acceptance as regulatory mechanisms. Personality and Individual Differences, 49(6), 645-650.

http://dx.doi.org/10.1016/j.paid.2010.05.041

Kabat-Zinn, J. (1982). An outpatient program in behavioral medicine for chronic pain patients based on the practice of mindfulness meditation: Theoretical considerations and preliminary results. General Hospital Psychiatry, 4(1), 33-47. http://dx.doi.org/10.1016/0163-8343(82)90026-3

Kabat-Zinn, J. (2003). Mindfulness-based interventions in context: Past, present, and future. Clinical Psychology: Science and Practice, 10(2), 144-156. http://dx.doi.org/10.1093/clipsy.bpg016

Keyes, C. L. M. (1998). Social well-being. Social psychology quarterly, 61(2), 121-140. http://dx.doi.org/10.2307/2787065

Lapierre, S., \& Desroches, C. (1997). Traduction et validation des Échelles de bien-être psychologique de Ryff. Trois-Rivières, Canada.: Université du Québec à Trois-Rivières.

Linehan, M. M. (1993). Cognitive-behavioral treatment of borderline personality disorder. Behaviour Research and Therapy. Guilford Press.

Little, B. R. (1983). Personal projects: A rationale and method for investigation. Environment and Behavior, 15(3), 273-309. http://dx.doi.org/10.1177/0013916583153002

Little, B. R., \& Chambers, N. (2000). Analyse des projets personnels: un cadre intégratif pour la psychologie clinique et le counseling. Revue québécoise de psychologie, 21, 153-189.

Little, B. R., Salmela-Aro, K., \& Phillips, S. D. (2007). Personal project pursuit. Goals, action, and human flourishing. Lawrence Erlbaum Associates.

MacKillop, J., \& Anderson, E. J. (2007). Further psychometric validation of the Mindful Attention Awareness Scale (MAAS). Journal of Psychopathology and Behavioral Assessment, 29(4), 289-293. http://dx.doi.org/10.1007/s10862-007-9045-1

Mitmansgruber, H., Beck, T. N., Höfer, S., \& Schüßler, G. (2009). When you don't like what you feel: Experiential avoidance, mindfulness and meta-emotion in emotion regulation. Personality and Individual Differences, 46(4), 448-453. http://dx.doi.org/10.1016/j.paid.2008.11.013

Moore, A., \& Malinowski, P. (2009). Meditation, mindfulness and cognitive flexibility. Consciousness and Cognition, 18(1), 176-186. http://dx.doi.org/10.1016/j.concog.2008.12.008

Öst, L.-G. (2008). Efficacy of the third wave of behavioral therapies: A systematic review and metaanalysis. Behaviour Research and Therapy, 46(3), 296-321. http://dx.doi.org/10.1016/j.brat.2007.12.005

Preacher, K. J., \& Hayes, A. F. (2008). Asymptotic and resampling strategies for assessing and comparing indirect effects in multiples mediator models. Behavior Research Methods, 40(3), 879-891.

http://dx.doi.org/10.3758/BRM.40.3.879

Roemer, L., Lee, J. K., Salters-Pedneault, K., Erisman, S. M., Orsillo, S. M., \& Mennin, D. S. (2009). Mindfulness and emotion regulation difficulties in generalized anxiety disorder: Preliminary evidence for independent and overlapping contributions. Behavior Therapy, 40(2), 142-154.

http://dx.doi.org/10.1016/j.beth.2008.04.001 
Ruiz, F. J. (2010). A review of acceptance and commitment therapy (ACT) empirical evidence: Correlational, experimental psychopathology, component and outcome studies. International Journal of Psychology and Psychological Therapy, 10(1), 125-162.

Ryan, R. M., \& Connell, J. P. (1989). Perceived locus of causality and internalization: Examining reasons for acting in two domains. Journal of Personality and Social Psychology, 57(5), 749-761. http://dx.doi.org/10.1037/0022-3514.57.5.749

Ryan, R. M., \& Deci, E. L. (2000). Self-determination theory and the facilitation of intrinsic motivation, social development, and well-being. American Psychologist, 55(1), 68-78. http://dx.doi.org/10.1037/0003-066X.55.1.68

Ryff, C. D., \& Keyes, C. L. M. (1995). The structure of psychological well-being revisited. Journal of Personality and Social Psychology, 69(4), 719-727. http://dx.doi.org/10.1037/0022-3514.69.4.719

Salmela-Aro, K., \& Little, B. R. (2007). Relational aspects of project pursuit. In B. R. Little, K. Salmela-Aro, \& S. D. Phillips (Eds.), Personal project pursuit. Goals, action and human flourishing (pp. 199-219). NewJersey: Lawrence Erlbaum Associates inc.

Sauer, S., \& Baer, R. A. (2010). Mindfulness and decentering as mechanisms of change in mindfulnessand acceptance-based interventions. Assessing mindfulness and acceptance processes in clients: Illuminating the theory and practice of change. (pp. 25-50). Oakland, CA, US: Context Press/New Harbinger Publications.

Sears, S., \& Kraus, S. (2009). I think therefore i om: cognitive distortions and coping style as mediators for the effects of mindfulness meditation on anxiety, positive and negative affect, and hope. Journal of clinical psychology, 65(6), 561-573. http://dx.doi.org/10.1002/jclp.20543

Segal, Z. V., Williams, J. M. G., \& Teasdale, J. D. (2002). Mindfulness-Based Cognitive Therapy for depression. A new approach to preventing relapse. New-York: The Guilford Press.

Shapiro, S. L., Astin, J. A., Bishop, S. R., \& Cordova, M. (2005). Mindfulness-based stress reduction for health care professionals: Results from a randomized trial. International Journal of Stress Management, 12(2), 164-176. http://dx.doi.org/10.1037/1072-5245.12.2.164

Shapiro, S. L., Brown, K. ., \& Biegel, G. M. (2007). Teaching self-care to caregivers: Effects of mindfulnessbased stress reduction on the mental health of therapists in training. Training and Education in Professional Psychology, 1(2), 105-115. http://dx.doi.org/10.1037/1931-3918.1.2.105

Shapiro, S. L., Carlson, L. E., Astin, J. A., \& Freedman, B. (2006). Mechanisms of mindfulness. Journal of Clinical Psychology, 62(3), 373-386. http://dx.doi.org/10.1002/jclp.20237

Shapiro, S. L., Oman, D., Thoresen, C. E., Plante, T. G., \& Flinders, T. (2008). Cultivating mindfulness: Effects on well-being. Journal of clinical psychology, 64(7), 840-862. http://dx.doi.org/10.1002/jclp.20491

Sheldon, K. M., \& Kasser, T. (1995). Coherence and congruence: Two aspects of personality integration. Journal of Personality and Social Psychology, 68(3), 531-543. http://dx.doi.org/10.1037/0022-3514.68.3.531

Sheldon, K. M., \& Kasser, T. (1998). Pursuing personal goals: Skills enable progress, but not all progress is beneficial. Personality and Social Psychology Bulletin, 24(12), 1319-1331. http://dx.doi.org/10.1177/01461672982412006

Sheldon, K. M., \& Kasser, T. (2001). Goals, congruence, and positive well-being: New empirical support for humanistic theories. Journal of Humanistic Psychology, 41(1), 30-50. http://dx.doi.org/10.1177/0022167801411004

Sheldon, K.M., \& Hoon, T. (2007). The multiple determination of well-being: Independent effects of positive traits, needs, goals, selves, social supports, and cultural contexts. Journal of Happiness Studies, 8(4), 565-592. http://dx.doi.org/10.1007/s10902-006-9031-4

Stauffer, M. D. (2007). Mindfulness in counseling and psychotherapy: A literature review and quantitative investigation of mindfulness competencies. Oregon State University.

Walach, H., Buchheld, N., Buttennmüller, V., Kleinknecht, N., \& Schmidt, S. (2006). Measuring mindfulness - the Freiburg Mindfulness Inventory (FMI). Personality and Individual Differences, 40, 1543-1555. http://dx.doi.org/10.1016/j.paid.2005.11.025

Watson, D., Clark, A. L., \& Tellegen, D. (1988). Development and validation of brief measures of positive and negative affect : The PANAS scales . Journal of Personality and Social Psychology, 54, 1063-1070. http://dx.doi.org/10.1037/0022-3514.54.6.1063 
Weinstein, N., Brown, K. ., \& Ryan, R. M. (2009). A multi-method examination of the effects of mindfulness on stress attribution, coping, and emotional well-being. Journal of Research in Personality, 43(3), 374-385. http://dx.doi.org/10.1016/j.jrp.2008.12.008 